\title{
Laser Scanning Ship Hulls to Support Hydrodynamic Simulations
}

\author{
Tamás Lovas ${ }^{1 *}$, Árpád József Somogyi ${ }^{1}$, Győző Simongáti ${ }^{2}$ \\ ${ }^{1}$ Department of Photogrammetry and Geoinformatics, Faculty of Civil Engineering, Budapest University of Technology and Economics, \\ H-1111 Budapest, Műegyetem rkp. 3., Hungary \\ ${ }^{2}$ Department of Aeronautics and Naval Architecture, Faculty of Transportation Engineering and Vehicle Engineering, Budapest \\ University of Technology and Economics, H-1111 Budapest, Műegyetem rkp. 3., Hungary \\ *Corresponding author, e-mail: lovas.tamas@emk.bme.hu
}

Received: 05 October 2021, Accepted: 22 November 2021, Published online: 06 December 2021

\begin{abstract}
Terrestrial laser scanning is an effective technology to capture high density and accurate point clouds about objects with complex geometry. Ship industry requires 3D hull models for multiple reverse engineering purposes; renovation, as-built analysis, simulations etc. The paper discusses how terrestrial laser scanning can be applied to capture ship hull geometry to support hydrodynamic simulations. It presents recommendations of survey geometry and methods considering scanner locations, reflectivity issues. Hydrodynamic simulations require specific types of surface models as inputs; data processing procedure is discussed how the point clouds are effectively transformed to models to be applied. Resource analysis is also included, such as duration of survey and processing, equipment to be used.
\end{abstract}

Keywords

laser scanning, point cloud, ship hull geometry, hydrodynamic simulation

\section{Introduction}

Surface-based surveying technologies are able to effectively support reverse engineering processes. In such cases there are no available models, drawings or plans about an engineering product or object that would be needed during reconstruction, reproduction or even for visualization, i.e., the physical model is the source of information of the end product $[1,2]$. Except some cases when the object to be modelled can be easily measured by some linear or simple measurements (e.g., indoor spaces of a building), i.e., it has regular shape and moderate size, the measurement is complex, often the originally regular shape is deformed. Therefore, in such cases surface-based measurements are preferred, i.e. data from the entire relevant surfaces are to be captured. Terrestrial laser scanning (TLS) and close range photogrammetry are still rapidly developing data acquisition methods in the field of civil engineering [3-7] mechanical engineering [8-11], and vehicle engineering [12, 13].

Ships are even more special from many aspects:

- The entire body of the vessel can be captured only out of water, which is either suspended or placed on structure that potentially cause occlusions and hence require thorough planning of surveying locations. In a shipyard (as in one of our cases) moving machines and crew around and on the ship can also block the line-of-sight between scanner and object or target.

- Ships are sizeable object, often hard to be moved in ideal positions for surveying by an instrument, nearby objects do not allow to locate instruments far enough from the ship.

- Ship body surfaces are not regular, difficult to be described by simple functions.

- Hydrodynamic simulation software packages in most cases require smoothened, corrected surface models as inputs.

Multiple related research works have been carried out in that addressed ship hull as-built modelling. Koelman [14] preferred to use photogrammetric methods to capture the ship geometry taking the advantage of being able to receive topological information due to human interpretation. The authors provide detailed, step-by-step information on the hull shape measurement. Ackermann et al. [15] measured not only the hull, but the propeller of the ship 
based on image sequences; photo-based or laser scanner based propeller modelling was the topic of many other researches, e.g., [16, 17]. Paoli and Razionale [18] applied high accuracy optical scanner mounted on anthropomorphic arm with two linear guides and scanned a $59 \mathrm{~m}$ yacht. Abbas et al. [19] applied photogrammetry for control point measurements to identify, model and correct the systematic errors of the laser scanner that has been used to capture the shape of the hull in laboratory environment. Burdziakowski and Tysiac [20] used photogrammetric survey (by 159 DSLR images) and terrestrial laser scanning (from 20 scan positions with Riegl VZ-400 scanner) to model a $44 \mathrm{~m}$ submarine. The vessel is painted black (that absorbs the laser beam), the team surveyed it in a rainy day, and they didn't use tie points (used ICP to register the point clouds instead). Despite the challenging circumstances and object they produced a remarkable hull model, merged the point clouds from different sources and analyzed the deviations. Roca-Pardiñas et al. [21] applied TLS for detecting asymmetries of boat hulls and used a $12 \mathrm{~m}$ yacht as test object. Vorobyev et al. [22] used the same type of scanner (Faro Focus 3D) as we did in some of our ship measurements; they used the model in load test measurements of a hull replica section. Bartoš et al. [23] also used both photogrammetric and TLS measurements for surveying $7 \mathrm{~m}$ long boats and discussed several encountered issues to be solved during their project.

The current paper discusses only TLS based measurements, involves ships with different sizes (from $7 \mathrm{~m}$ to $105 \mathrm{~m}$ ) and considers hydrodynamic simulations as target application.

\section{Laser scanning of ships}

\subsection{Overall information}

Surveying methods are presented in this paper through three examples: a self-propelled inland vessel scanned in Germany in 2019, and one sailing boat designed for sailing races scanned in Budapest in 2020 (Fig. 1).

Previously ship geometry for hydrodynamic simulations was defined by manual measurements using tapes and rod frames to get the primary dimensions in dedicated sections of the ship. In the discussed cases the simulations required high density accurate surface models. Considering the geometric requirements and the circumstances we decided to capture the geometry by terrestrial laser scanning.

In order to get homogeneous point distribution within the measurement range of the scanners, to avoid too small reflection angles and to ensure optimal matching of the point clouds, scanner locations has certain limitations. However, in the discussed cases scan station positions were limited by the ships' close environment, unavoidable occlusions.

\subsection{The inland vessel}

The laser scanned vessel (name: MS ULM) is a $105 \mathrm{~m}$ ship (Fig. 2) that have been removed from water in Erlenbach, Germany in the fall of 2019 for renovation works.

There was a limited time window by the end of October (when the weather can be rainy any day in this region of Germany), the ship was at a shipyard and intensive renovation works were in progress. As backup and for research analysis purposes we prepared with two scanners, a Surphaser 400 and a Faro Focus 3D 120S, Table 1 Contains the technical specifications.

Marker spheres (diameter: 139 and $145 \mathrm{~mm}$ ) were used for both scanners as targets that supports accurate matching of point clouds, georeferencing was not needed. Both scanners used the same set of spheres, therefore both scanners worked in parallel (Fig. 3.). Ship workers and crew was asked to avoid scanners' line-of-sight during measurements. Scanning resolution (point spacing) for both instruments was set to $6 \mathrm{~mm}$ at $10 \mathrm{~m}$ distance, while scanning time was $3 \mathrm{~min} 30 \mathrm{sec}$ for Faro and $3 \mathrm{~min}$ for Surphaser.

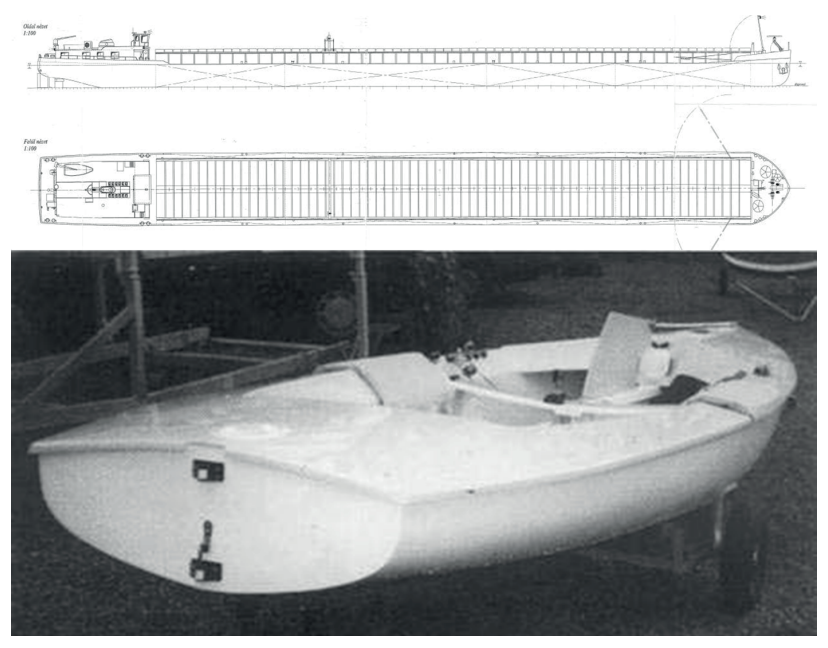

Fig. 1 Inland vessel (top), racing sailboat (bottom)

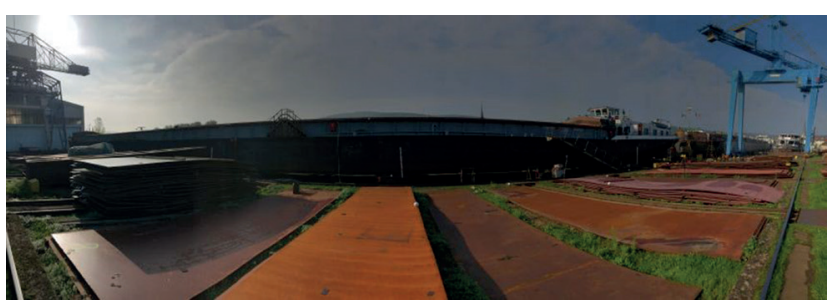

Fig. 2 The vessel and its environment 
Table 1 Technical parameters of the applied scanners

\begin{tabular}{lcc}
\hline & Surphaser 400 & Faro Focus 3D 120S \\
\hline Ranging accuracy & $0.7 \mathrm{~mm}$ & $2 \mathrm{~mm}$ \\
& $0.07 \mathrm{~mm} @ 90 \%$ refl. $\mid$ & $0.3 \mathrm{~mm} @ 90 \%$ refl. $\mid$ \\
Ranging noise & $0.15 \mathrm{~mm} @ 10 \%$ refl. & $0.6 \mathrm{~mm} @ 10 \%$ refl. at \\
& at $1 \mathrm{~m}-15 \mathrm{~m}$ & $1 \mathrm{~m}-10 \mathrm{~m}$ \\
Laser Wavelength & $1550 \mathrm{~nm}$ & $905 \mathrm{~nm}$ \\
Max. point density & $0.75 \mathrm{~mm} / 10 \mathrm{~m}$ & $1.5 \mathrm{~mm} / 10 \mathrm{~m}$ \\
spacing & $832.000 \mathrm{pts} / \mathrm{sec}$ & $975.000 \mathrm{pts} / \mathrm{sec}$ \\
Repetition rate & Yes & Yes \\
Image capability & $\sim$ EUR 150.000 & $\sim$ EUR 40.000 \\
price & & \\
\hline
\end{tabular}

Table 2 shows the results of the survey.

Point clouds captured from different scan positions have been registered (merged) by using the spheres to join the datasets and cleaned by deleting the irrelevant point that have not been reflected from the vessel. These operations have been executed for both the Faro and Surphaser point clouds, independently. Then, a deviation map has been derived by comparing the result datasets from the two scanners, using the Surphaser point cloud as reference (Fig. 4). As it can be seen on the figure most deviation values are smaller than $5 \mathrm{~mm}$. The reason of the higher values is that the scanners were set on different scan stations, therefore scanning geometry results higher noise in some parts (e.g., at low incident angles).

\subsection{The racing sailboat}

Knowing the exact shape of a racing boat is required to predict its racing potential. In this particular case there were no blueprints available on the boat and the owner among other improvements - intended to extend the hull in order to get better hydrodynamic performance.

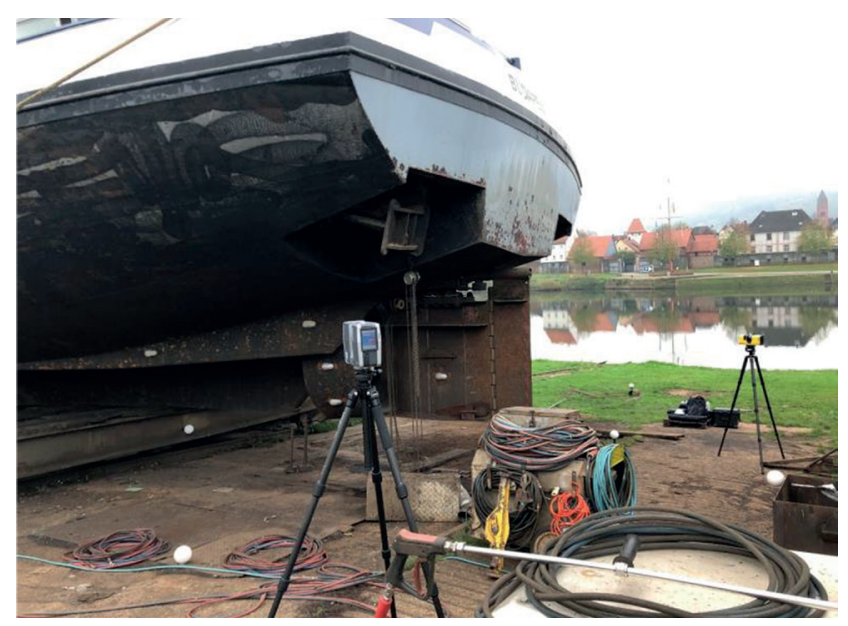

Fig. 3 Scanners and targets at the back of barge
Table 2 Survey results

\begin{tabular}{lcc}
\hline & Surphaser 400 & Faro Focus 3D 120S \\
\hline $\begin{array}{lcc}\text { No. of scan stations } \\
\text { No. of points from barge }\end{array}$ & 366.000 .000 & 33 \\
$\begin{array}{l}\text { Max. residual of } \\
\text { matching }\end{array}$ & $3 \mathrm{~mm}$ & 250.000 .000 \\
Processing software & Leica Cyclone 8 & Faro Scene 2018 \\
\hline
\end{tabular}

The boat's surface was matte black; since it highly absorbed the laser beams, it turned out that only points close to the scanner were captured (and with high noise rate) (Fig. 5). It couldn't be scanned applying reasonable number of scan stations, therefore we decided to paint the ship's body, since it was planned to be furbished and refined afterwards anyway.

The processed point cloud of the boat contains 7.5 million points that is unnecessary for deriving the required product. Moreover, the simulation software used by experts prefer surface or solid models instead of point clouds. Therefore, the TIN model of the boat has been created that resulted 535.000 triangles after manual corrections (Fig. 6(a)). This mesh model was the base for obtaining the CAD surface model that contains 2.858 faces (Fig. 6(b)).

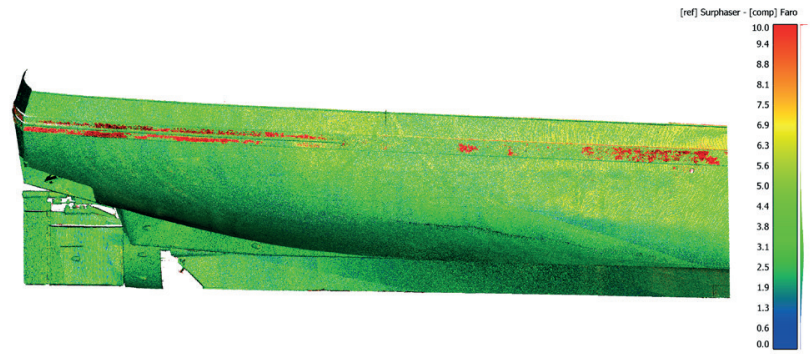

Fig. 4 Deviation map of the two point clouds (Surphaser - reference and Faro - compared)

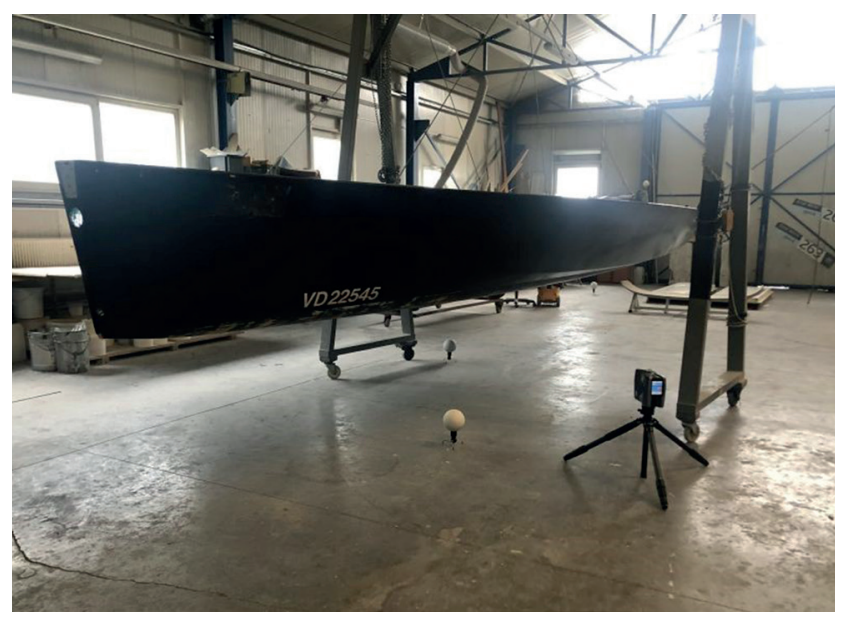

Fig. 5 Scanning the matte black surface of the race boat 

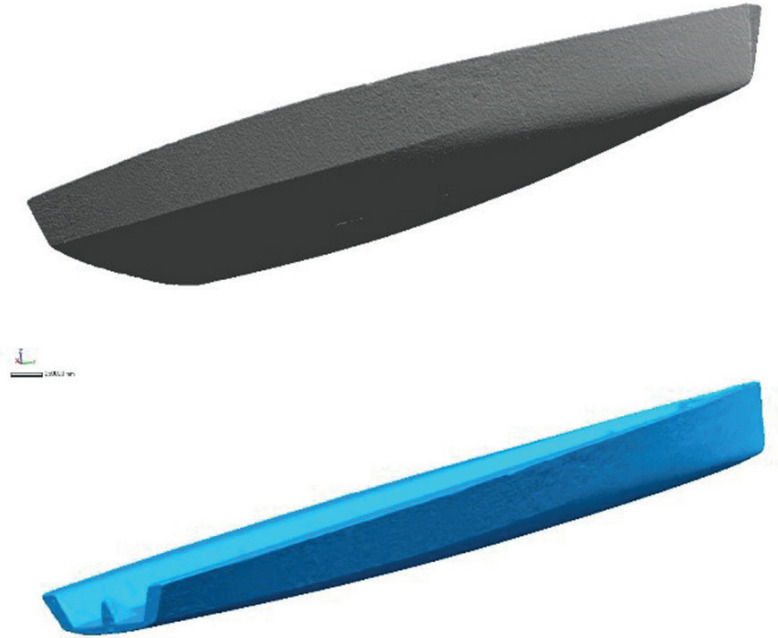

$\underline{L}$

Fig. 6 Boat surface models - TIN (top), CAD faces (bottom)

\section{Modelling}

The co-registered, cleaned, resampled point clouds were meshed in Geomagic DesignX software environment. The high geometric resolution of the mesh enables to detect and measure deformations (Fig. 7).

The point cloud enables deriving cross sections of the hull. These sections can be taken at any locations, enabling investigations that need the original geometry

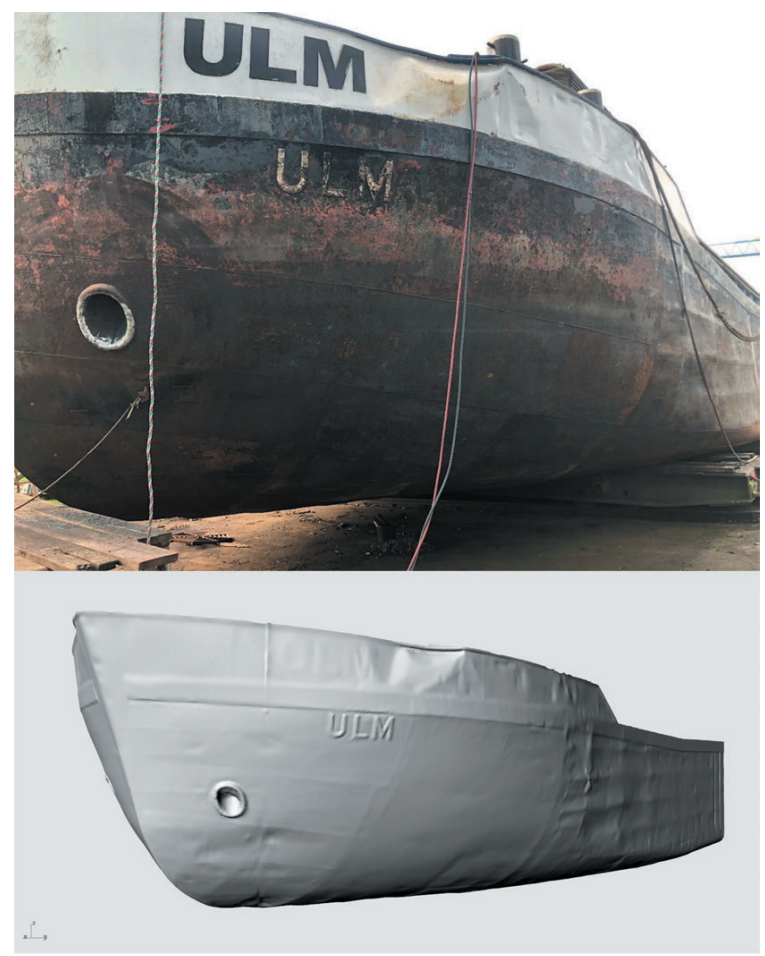

(a) (e.g., in case of damage analysis). The surface model required by hydrodynamic simulations has been derived using these 2D sections. The resolution (level of detail) of the model can be improved by involving more $2 \mathrm{D}$ sections, however, this modeling step require reasonable trade-off between computing capacity and achievable simulation accuracy (Fig. 8).

Hydrodynamics simulations required simplified models; by keeping the basic geometry of the hull, the surface has been smoothened. The corrected model can be seen on Fig. 9.
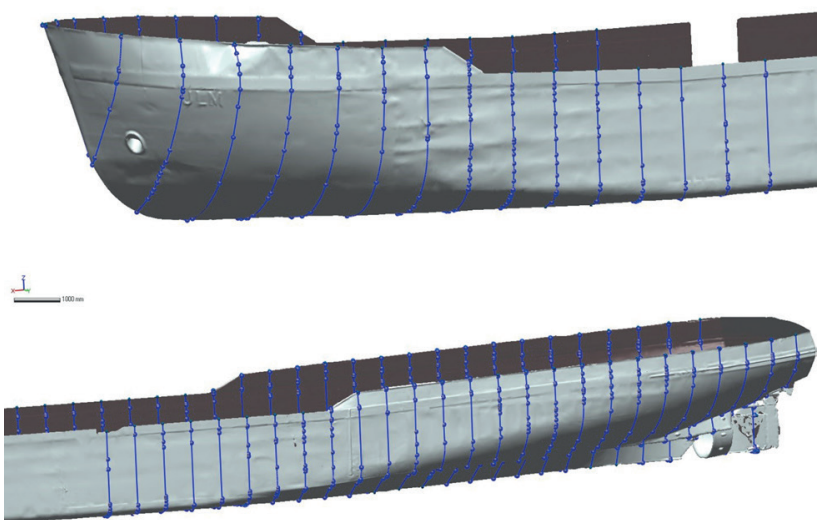

i.

Fig. 8 Cross-sections taken at pre-defined locations

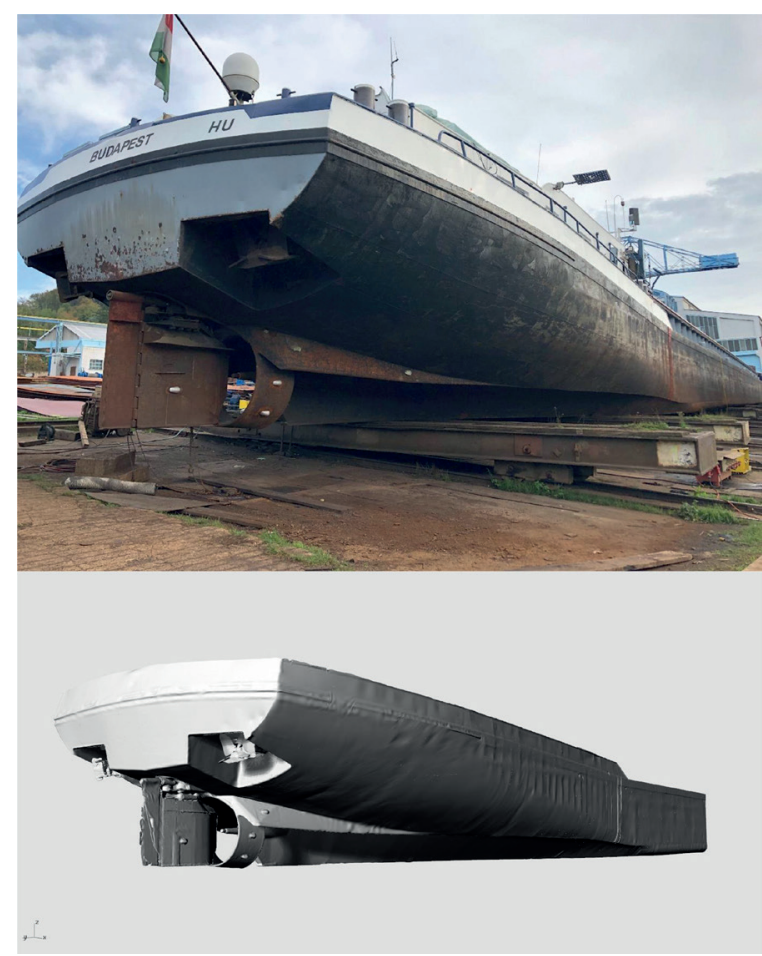

(b)

Fig. 7 a) The result mesh model of the vessel bow, b) The result mesh model of the vessel stern 


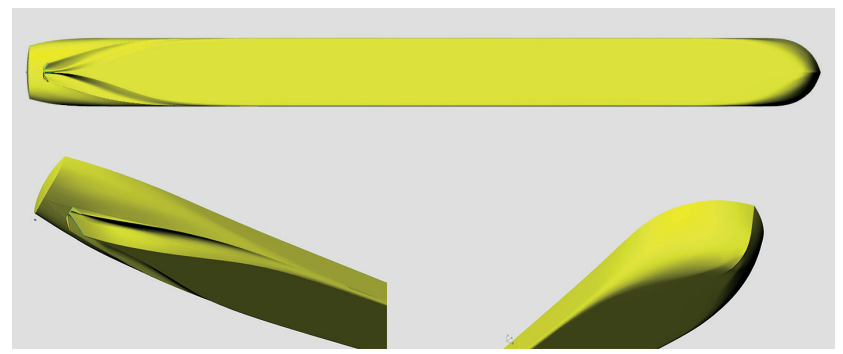

Fig. 9 Corrected models for hydrodynamic simulations

4 Model-based calculations, simulations, measurements The scan of the inland vessel was primarily necessary for enabling hydrodynamic improvements on the vessel. The owner and operator are involved in a project in which "greening" of the inland vessels and finding solutions for this was the main goal. Hence analysis was initiated for particular vessels in the fleet of the shipping company. The vessel has a relatively blunt bow and so has a potential for modification for reducing the resistance and hence the fuel consumption of the ship. Unfortunately, the owner does not have any drawing and plan about the ship, so modification of the hull geometry was only possible after its geometric survey enabling reverse engineering.

After TLS measurement was done, the resulting database enabled first to create a smooth and geometrically accurate surface model of the vessel and second to re-design the bow of the vessel. For hydrodynamic analysis 3 new bow forms of different sizes and cross-sections were elaborated and analyzed by CFD simulations. Exaggerated wave patterns along the 3 bow forms are shown on Fig. 10. (Differences of models are only in horizontal and transversal sections, hence not visible on the figure.)

Moreover, having the surface geometry, hydrostatic calculations could also be done which were necessary to determine the change in cargo carrying capacity due to the new bow form. (As a side product, with hydrostatic calculations it was possible to provide the owner with a so-called capacity plan of the vessel.)

In addition to the above, the very detailed point cloud allowed the naval architects to check the current state of the hull, from the geometrical point of view. Not only size of local deformations (e.g., that of hull plates) could be quantified, but the global distortion of the sections as well.

\section{Future perspectives}

This cooperation between surveying and naval experts showed how the technical improvements and equipment at one side can help other engineering fields. From the naval architect's point of view, it is not unique that a usable technical documentation does not exist. The reverse engineering

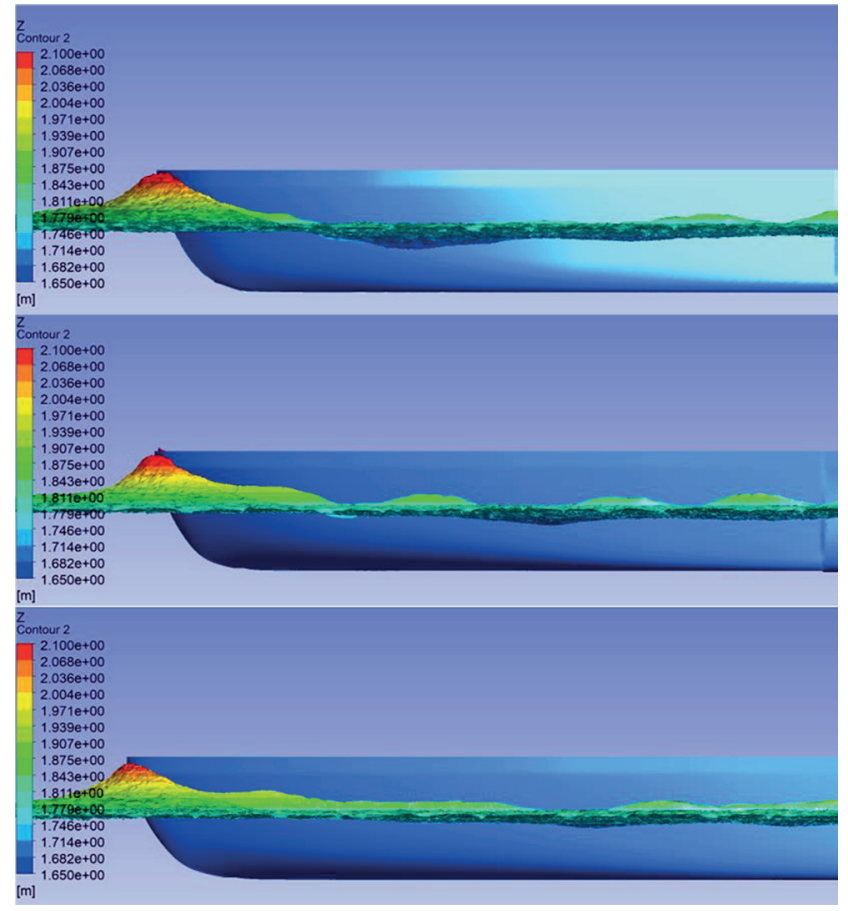

Fig. 10 CFD analysis of the 3 bow versions

could be very helpful in cases when propeller or rudder sections and performance data is not available, but for development it would be required.

For reconstruction of existing hulls, TLS can provide a very reliable basis. By using the surface generated on the captured point clouds, it is even feasible to cut with CNC new structural stiffeners that will perfectly fit to the irregular shape of the hull. This could result in increased accuracy and time savings during construction.

As shown on previous pictures, deformations, damages can be detected and even quantified using such scanning method. Therefore, TLS can serve comparison analysis when as-is state should be measured to the optimal solution. By this, a probably expensive reconstruction and the gain achieved as a result could be set side by side and economic feasibility can be assessed.

\section{Conclusions}

The paper discusses both data acquisition and processing (modeling) aspects regarding laser scanning of ship hulls. The investigations proved that the geometry of the hull can be captured even in non-ideal circumstances with the required accuracy requirements (below $5 \mathrm{~mm}$ relative accuracy); i.e., scan stations close to object, absorbing color, occlusions. The resulted point cloud and the obtained mesh models effectively support hydrodynamic simulations and hence geometrical optimization of the ships. 


\section{Acknowledgement}

The research reported in this paper was supported by the Higher Education Excellence Program of the Ministry of Human Capacities in the frame of the Water Sciences $\&$ Disaster Prevention research area of BME (BME FIKP-VÍZ).

\section{References}

[1] Raja, V., Fernandes, K. J. (eds.) "Reverse Engineering: An Industrial Perspective", Springer, London, UK, 2008. https://doi.org/10.1007/978-1-84628-856-2

[2] Górski, F., Kuczko, W., Wichniarek, R., Zawadzki, P. "Application of close-range photogrammetry in reverse engineering", presented at 7th International DAAAM Baltic Conference, Industrial Engineering, Tallinn, Estonia, April, 22-24, 2010.

[3] Berényi, A., Lovas, T., Barsi, Á., Dunai, L. "Potential of terrestrial laserscanning in load test measurements of bridges", Periodica Polytechnica Civil Engineering, 53(1), pp. 25-33, 2009. https://doi.org/10.3311/pp.ci.2009-1.04

[4] Suchocki, C., Katzer, J., Rapiński, J. "Terrestrial laser scanner as a tool for assessment of saturation and moisture movement in building materials", Periodica Polytechnica Civil Engineering, 62(3), pp. 694-699, 2018.

https://doi.org/10.3311/PPci.11406

[5] Sengoz, B., Topal, A., Tanyel, S. "Comparison of pavement surface texture determination by sand patch test and 3D laser scanning", Periodica Polytechnica Civil Engineering, 56(1), pp. 73-78, 2012. https://doi.org/10.3311/pp.ci.2012-1.08

[6] Bitelli, G., Simone, A., Girardi, F., Lantieri, C. "Laser Scanning on Road Pavements: A New Approach for Characterizing Surface Texture", Sensors, 12(7), pp. 9110-9128, 2012. https://doi.org/10.3390/s120709110

[7] Xu, X., Yang, H. "Intelligent crack extraction and analysis for tunnel structures with terrestrial laser scanning measurement", Advances in Mechanical Engineering, 11(9), pp. 1-7, 2019. https://doi.org/10.1177/1687814019872650

[8] Larsson, S., Kjellander, J. A. P. "Motion control and data capturing for laser scanning with an industrial robot", Robotics and Autonomous Systems, 54(6), pp. 453-460, 2006. https://doi.org/10.1016/j.robot.2006.02.002

[9] Poozesh, P., Baqersad, J., Niezrecki, C., Avitabile, P., Harvey, E., Yarala, R. "Large-area photogrammetry based testing of wind turbine blades", Mechanical Systems and Signal Processing, 86(B), pp. 98-115, 2017. https://doi.org/10.1016/j.ymssp.2016.07.021

[10] Lee, H., Rhee, H. "3-D measurement of structural vibration using digital close-range photogrammetry", Sensors and Actuators, A: Physical, 196, pp. 63-69, 2013. https://doi.org/10.1016/j.sna.2013.03.010

[11] Baqersad, J., Poozesh, P., Niezrecki, C., Avitabile, P. "Photogrammetry and optical methods in structural dynamics - A review", Mechanical Systems and Signal Processing, 86(B), pp. 17-34, 2017. https://doi.org/10.1016/j.ymssp.2016.02.011
The research reported in this paper was supported by BOSS5D project under grant agreement No. 2017-1.3.1VKE-2017-00040 (2018-2021). Application of networking technologies in the field of design, manufacturing, assembly, maintenance and related services of steel structures.

[12] Liu, J., Sun, Q., Fan, Z., Jia, Y. "TOF lidar development in autonomous vehicle", In: 2018 IEEE 3rd Optoelectronics Global Conference (OGC), Shenzhen, China, 2018, pp. 185-190. https://doi.org/10.1109/OGC.2018.8529992

[13] Ding, F., Zhao, Y., Guo, L., Zhang, M., Li, L. "Obstacle detection in hybrid cross-country environment based on Markov random field for unmanned ground vehicle", Discrete Dynamics in Nature and Society, 2015, Article ID 540968, 2015. https://doi.org/10.1155/2015/540968

[14] Koelman, H. J. "Application of a photogrammetry-based system to measure and re-engineer ship hulls and ship parts: An industrial practices-based report", Computer-Aided Design, 42(8), pp. 731$743,2010$. https://doi.org/10.1016/j.cad.2010.02.005

[15] Ackermann, S., Menna, F., Scamardella, A., Troisi, S. "Digital photogrammetry for high precision $3 \mathrm{D}$ measurements in shipbuilding field", In: Proceedings of the CIRP ICME '08 International Conference, Naples, Italy, 2008, pp. 6-11.

[16] Menna, F., Troisi, S. "Low cost reverse engineering techniques for 3d modelling of propellers", In: International Archives of Photogrammetry, Remote Sensing and Spatial Information Sciences, Commission V Symposium, Newcastle upon Tyne, UK, 2010, pp. $452-457$.

[17] Guan, G., Gu, W. "Reconstruction of propeller and complex ship hull surface based on reverse engineering", Journal of Marine Science and Technology, 27(6), pp. 498-504, 2019. https://doi.org/10.6119/JMST.201912_27(6).0002

[18] Paoli, A., Razionale, A. V. "Large yacht hull measurement by integrating optical scanning with mechanical tracking-based methodologies", Robotics and Computer-Integrated Manufacturing, 28(5), pp. 592-601, 2012. https://doi.org/10.1016/j.rcim.2012.02.010

[19] Abbas, M. A., Lichti, D. D., Chong, A. K., Setan, H., Majid, Z., Lau, C. L., Idris, K. M., Ariff, M. F. M. "Improvements to the accuracy of prototype ship models measurement method using terrestrial laser scanner", Measurement: Journal of the International Measurement Confederation, 100, pp. 301-310, 2017. https://doi.org/10.1016/j.measurement.2016.12.053

[20] Burdziakowski, P., Tysiac, P. "Combined Close Range Photogrammetry and Terrestrial Laser Scanning for Ship Hull Modelling", Geosciences, 9(5), Article No. 242, 2019. https://doi.org/10.3390/geosciences9050242

[21] Roca-Pardiñas, J., López-Alvarez, F., Ordónez, C., Menéndez, A., Bernardo-Sánchez, A. "Terrestrial laser scanning used to detect asymmetries in boat hulls", Optical Engineering, 51(1), Article No. $013605,2012$. 
[22] Vorobyev, A., Garnier, F., van Dijk, N. P., Hagman, O., Gamstedt, E. K. "Evaluation of displacements by means of 3D laser scanning in a mechanically loaded replica of a hull section of the Vasa ship", Digital Applications in Archaeology and Cultural Heritage, 11, Article ID e00085, 2018.

https://doi.org/10.1016/j.daach.2018.e00085
[23] Bartoš, K., Pukanská, K., Repáň, P., Kseňak, L., Sabová, J. "Modelling the Surface of Racing Vessel's Hull by Laser Scanning and Digital Photogrammetry", Remote Sensing, 11(3), Article No. 1526, 2019.

https://doi.org/10.3390/rs11131526 